\title{
IMPLEMENTATION OF THREE PHASE-DISCONTINUOUS SPACE VECTOR MODULATION USING SINGLE DSC-PWM MODULE
}

The paper presents an implementation of a discontinuous space vector modulation of three phase inverter. The modulation is implemented in a DSC (Digital Signal Controller) using only one PWM module. Phases of the inverter work in a complementary mode. This implementation gives an assumption to use one DSC for simultaneous controlling of several three phase inverters. Furthermore, a simulation comparison of discontinuous and continuous space vector modulation is made.

Keywords: Three-phase inverter, space vector modulation, discontinuous space vector modulation, pulse width modulation.

\section{Introduction}

Thanks to its simplicity and ability to supply three phase load by a voltage with variable frequency and magnitude, three phase voltage inverters have a wide use. Control of these inverters plays a big role. The simplest and the most widely used control method is the carrier-based sine-triangle PWM. Its drawback is low use of DC-bus voltage. Next method with very good preferences is a Space Vector Modulation (SVM). It has also a lot of variants and improvements. Discontinuous Space Vector Modulation (marked as DPWM) is one of them. It suffers from worst properties of voltage and current waveforms, but also it allows the control to be simpler and also leads to less switching losses.

\section{Space Vector Modulation}

We can look at the Three-phase voltage, created by inverter like at a single voltage vector in a vector space. It is rotating by an angular speed of electric field and is stated by its amplitude. The idea of SVM is to create this vector using switching elements of the inverter. The inverter can create six voltage vectors $\left(\mathrm{U}_{0}, \mathrm{U}_{60}, \mathrm{U}_{120}, \mathrm{U}_{180}, \mathrm{U}_{240}\right.$, $\left.\mathrm{U}_{300}\right)$ and two zero vectors $(0000,0111)$, which set in by switching on all of the top or bottom transistors.

It is obvious from Fig. 1 that voltage vectors divide a space into six sectors. Approximation of a desired voltage vector is done by creating two vectors that border actual sector within every PWM period. According to desired magnitude of the voltage vector, both



Fig. 1 Voltage vectors of the inverter [1]

zero vectors are applied as well. Mathematical consideration is shown bellow.

$$
\frac{1}{T} \int_{n T}^{(n+1) T} U_{\text {out }} d t=\frac{1}{T}\left(T_{1} U_{x}+T_{2} U_{x \pm 60}\right)
$$

Where:

$T[\mathrm{~s}]$ is the period of PWM signal,

$U_{\text {out }}[\mathrm{V}]$ is the magnitude of the reference voltage vector

$U_{x}[\mathrm{~V}]$ and $U_{x \pm 60}[\mathrm{~V}]$ are the magnitudes of the inverter voltage vectors

$T_{1}[\mathrm{~s}]$ and $T_{2}[\mathrm{~s}]$ are the durations of the respective voltage vectors

\footnotetext{
* Stepan Janous ${ }^{1}$, Jozef Sedlak ${ }^{2}$, Michal Prazenica ${ }^{3}$, Jozef Kuchta ${ }^{4}$

${ }^{1}$ Department of Electromechanics and Power Electronics, Faculty of Electrical Engineering, University of West Bohemia, Czech Republic

${ }^{2}$ Department of Mechatronics and Electronics, Faculty of Electrotechnical Engineering, University of Zilina, Slovakia,

E-mail: jozef.sedlak@fel.uniza.sk

${ }^{3}$ Department of Mechatronics and Electronics, Faculty of Electrotechnical Engineering, University of Zilina, Slovakia

${ }^{4}$ EVPU, a.s. Nova Dubnica, Slovakia
} 
Equation 1 doesn't deal with zero vectors. Therefore, it is valid only if sum of $U_{x}$ and $U_{x \pm 60}$ gives a vector with the same amplitude as vector Uout has. If we assume that the change of Uout within one period is small, we can rewrite Eq. 1 as:

$$
U_{\text {out }}(n T)=\frac{1}{T}\left(T_{1} U_{x}+T_{1} U_{x \pm 60}\right)
$$

And if we take zero vectors into account, we get:

$$
T_{p w m} U_{o u t}=T_{1} U_{x}+T_{2} U_{x \pm 60}+\frac{T_{0}}{2}\left(0_{000}\right)+\frac{T_{2}}{2}\left(0_{111}\right)
$$

, where

$0_{000}[\mathrm{~V}]$ and $0_{111}[\mathrm{~V}]$ are the zero vectors of the inverter.

These zero vectors have a strong influence on a shape of inverter voltage. If we know a magnitude of desired voltage vector and an angle between this vector and the closest inverter voltage vector, we can calculate times $T_{1}, T_{2}$ and $T_{0}$ as follows:

$$
\begin{aligned}
& T_{2}=\frac{2 \cdot U_{\text {out }} T_{p w m} \cdot \sin \alpha}{U_{\text {vect }} \cdot \sqrt{3}} \\
& T_{1}=\frac{\cos \alpha U_{\text {out }} T_{p w m}-0.5 U_{\text {vect }} T_{2}}{U_{\text {vect }}} \\
& T_{0}=T_{p w m}-\left(T_{1}+T_{2}\right)
\end{aligned}
$$

$\alpha$ is the angle between the respective inverter vector and the reference voltage vector,

$T_{0}$ [s] is the duration of both zero vectors

$U_{\text {vect }}[\mathrm{V}]$ is a magnitude of inverter voltage vectors, and $U_{d c}[\mathrm{~V}]$ is an inverter supply voltage.

$$
U_{v e c t}=\frac{2}{3} U_{d c}
$$

In Fig. 1, the combination of upper transistors in a conducting state is listed next to every inverter-voltage vector. As an example for vector $U_{60}$, (110) means that upper transistors in first and second branch are in the conducting state. Transistors are switched complementary in every branch. Based on knowledge of creating respective vectors it is easy to define the switching times of upper

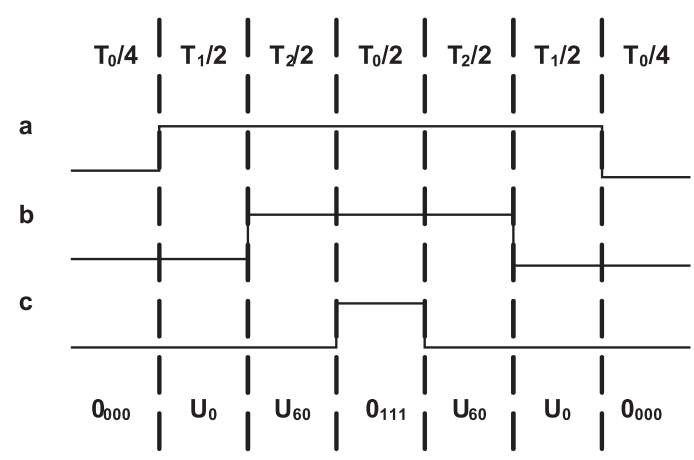

Fig. 2 Switching times assignment of the upper transistors in first sector during PWM period [1] transistors in terms of every PWM period. Composition of the switching states is different for every sector. In Fig. 2 we have an example for 1st sector. a, b and c are the respective branches.

Thanks to appropriate arrangement of the voltage vectors it is achieved that every transistor is once switched on and once switched off in every PWM period. It is obvious from Fig. 2 that a switchover in $\mathrm{c}$ branch is made only because of change from one zero vector to another zero vector. It leads us to one possible simplification of the switching scheme. This is in literature called Discontinuous Space Vector Modulation. Its switching scheme is in Fig. 3 [2], [3], [1].

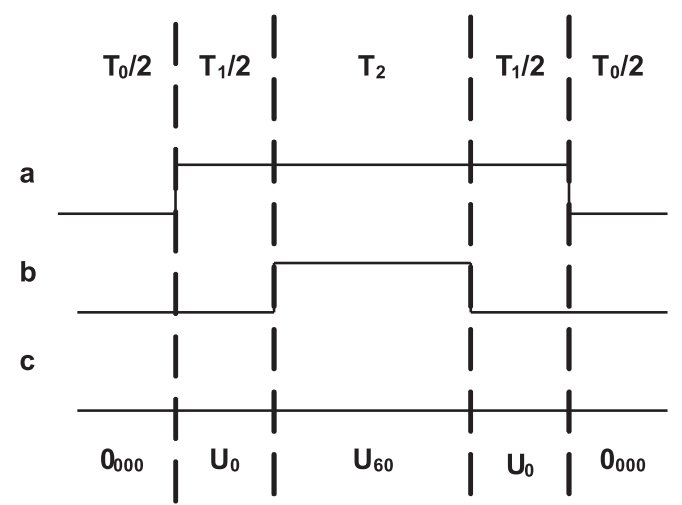

Fig. 3 Switching times assignment of the upper transistors in first sector during PWM period for Discontinuous Space Vector Modulation [1]

\section{Implementation of Discontinuous Space Vector Modulation in a Digital Signal Processor}

Exactly, the fact that in the terms of every PWM period transistors in one branch don't change their state gives an assumption to drive the whole three-phase inverter with only one PWM module. Digital Signal Controller by Texas Instruments TMS320F28335 has six PWM modules. Every module has its own register to set up a PWM period and also has two compare registers, as we can see in Fig.4. If we are going to use a DPWM, we can use these two registers for controlling two branches.



Fig. 4 Principle of the PWM module function [4]

In Fig. 5 we have a reference waveform for one branch of the inverter calculated by an algorithm of DPWM in Code Composer Studio v4. TBPRD is a register that defines the length of the PWM 
period. TBCTR is a counter that is incrementing until it reach the TBPRD value and then starts to decrement until zero. We can set up some events during PWM period with CMPA and CMPB registers. Mainly switching of a PWM output.



Fig. 5 Reference for one branch of the inverter

It is necessary to switchover a dispatching of the compare registers to the inverter branches due to an actual sector of the reference vector [4].

\section{Simulation comparison of continuous and discontinuous SVM}

We used MatLab-Simulink software in order to compare these two types of control with regard to quality of output parameters. The proposed simulated layout is in Fig. 6. In Fig. 7 reference waveforms for continuous SVM and in Fig. 8 for DPWM are shown.

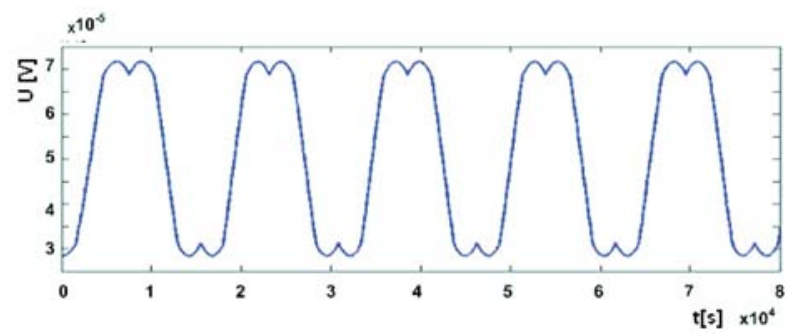

Fig. 7 Reference waveform for single phase in a case of continuous SVM

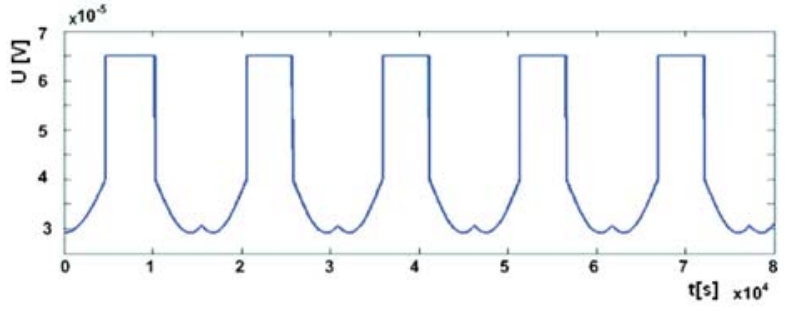

Fig. 8 Reference waveform for single phase in a case of DPWM

Currents were simulated with the use of mathematical model of an ideal three-phase inverter, which supplied RL load. Waveforms of currents were shown in Figs. 9 and 10 respectively.

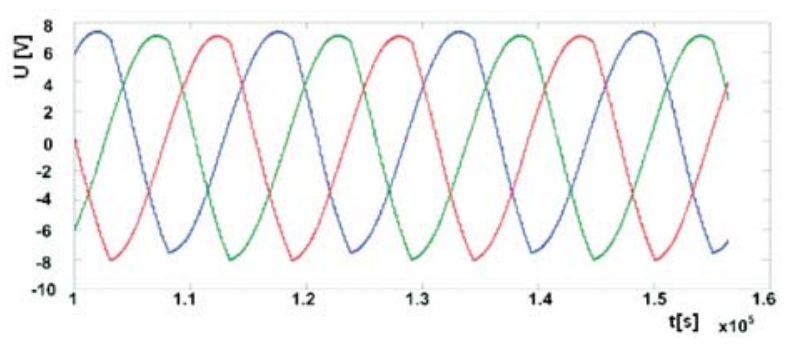

Fig. 9 Currents in a case of DPWM

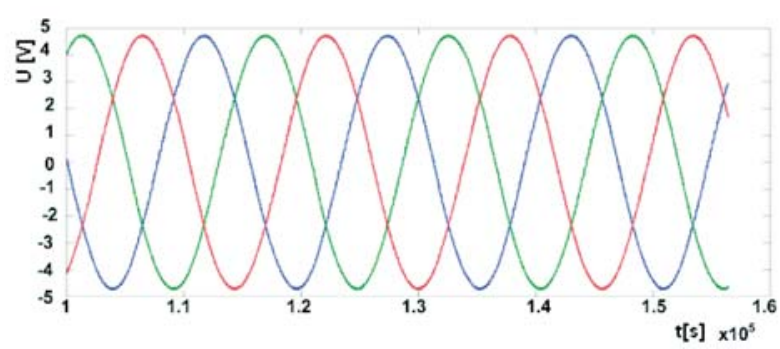

Fig. 10 Currents in a case of continuous SVM

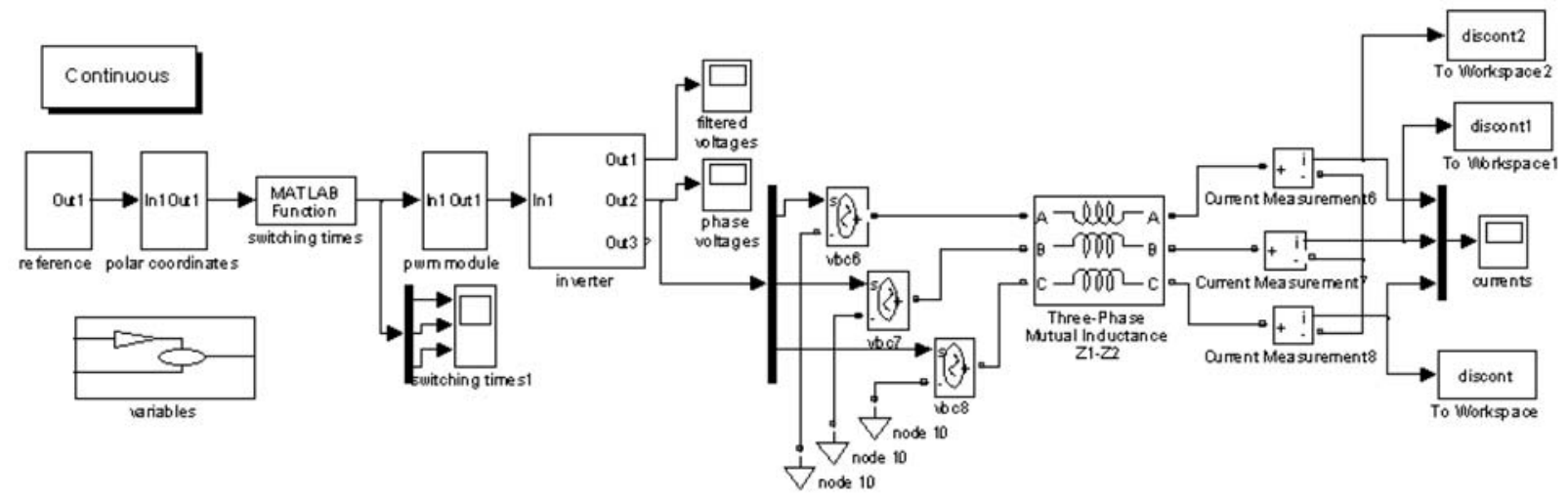

Fig. 6 Simulating scheme 




Fig. 11 Amplitude spectrum of harmonic components (DPWM)



Fig. 12 Amplitude spectrum of harmonic components (continuous SVM)

lation. We showed that DPWM can be implemented in DSP using only one PWM module. It means a great opportunity to save control accessories in some three-phase power systems, such as motor drives. However, a quality of current waveforms is worst in case of DPWM.

\section{Acknowledgement}

This paper was created thanks to the project ITMS 26220220078.

\section{References}

[1] Space-Vector PWM With TMS320C24x/F24x Using Hardware and Software Determined Switching Patterns, [27.03.2013], available on website: http://www.ti.com/lit/an/spra524/spra524.pdf

[2] DORIN O. NEACSU: Space Vector Modulation - An Introduction, ICEON'01

[3] IQBAL, A., AHMED, M., KHAN M.: Abu-Rub H.: Generalised Simulation and Experimental Implementation of Space Vector PWM Technique of a Three-phase Voltage Source Inverter, Intern. J. of Engineering, Science and Technology, vol. 2, No. 1, pp. $112,2010$.

[4] TMS320x280x, 2801x, 2804x Enhanced Pulse Width Modulator (ePWM) Module [27.03.2013], available on website: http://www.ti.com/lit/ug/spru791f/spru791f.pdf

[5] DRGONA, P., PRIKOPOVA, A., FRIVALDSKY, M., PRIECINSKY, M.: Simulation Based Method for Design and Application of Digital Control System, Communications - Scientific Letters of the University of Zilina, No. 2a, 2011, ISSN 1335-4205.

[6] BRANDT, M., RAFAJDUS, P., PENIAK, A., MICHALIK, J.: Diagnostics System of Power Transformers Supported by Finite Element Analysis, SPEEDAM 2012, ISBN 978-1-4673-1300-1.

[7] ZASKALICKA, M., ZASKALICKY, P., BENOVA, M., ABDALMULA, M. A. R., DOBRUCKY, B.: Analysis of Complex Time Function of Converter Output Quantities Using Complex Fourier Transform/Series. Communications - Scientific Letters of the University of Zilina, No. 1(12), pp. 23-30, 2010.

[8] ZASKALICKY, P., DOBRUCKY, B.: Complex Fourier-series Mathematical Model of a Three-Phase Inverter with Improved PWM Output Voltage Control; Elektronika ir Elektrotechnika, Kaunas, No. 7 (123), pp. 65-68, 2012. 